OPEN ACCESS

Edited by:

Victor Faundez,

Emory University, USA

Reviewed by:

Qian Cai,

Rutgers University, USA

Zhexing Wen,

Emory University School of Medicine,

USA

*Correspondence:

Andrea Degl'Innocenti

andrea.deglinnocenti@iit.it

Anna D'Errico

anna.derrico@biophys.mpg.de

Specialty section:

This article was submitted to

Neurogenomics,

a section of the journal

Frontiers in Genetics

Received: 21 December 2016 Accepted: 08 February 2017

Published: 21 February 2017

Citation:

Degl'Innocenti A and D'Errico A (2017) Regulatory Features for Odorant Receptor Genes

in the Mouse Genome.

Front. Genet. 8:19.

doi: 10.3389/fgene.2017.00019

\section{Regulatory Features for Odorant Receptor Genes in the Mouse Genome}

\author{
Andrea Degl'Innocenti ${ }^{1,2,3 *}$ and Anna D'Errico ${ }^{1 \text { * }}$ \\ ${ }^{1}$ Max Planck Institute of Biophysics, Frankfurt am Main, Germany, ${ }^{2}$ Cell and Developmental Biology Unit, Department of \\ Biology, University of Pisa, Pisa, Italy, ${ }^{3}$ Center for Micro-BioRobotics, Italian Institute of Technology, Sant'Anna School of \\ Advanced Studies, Pisa, Italy
}

The odorant receptor genes, seven transmembrane receptor genes constituting the vastest mammalian gene multifamily, are expressed monogenically and monoallelicaly in each sensory neuron in the olfactory epithelium. This characteristic, often referred to as the one neuron-one receptor rule, is driven by mostly uncharacterized molecular dynamics, generally named odorant receptor gene choice. Much attention has been paid by the scientific community to the identification of sequences regulating the expression of odorant receptor genes within their loci, where related genes are usually arranged in genomic clusters. A number of studies identified transcription factor binding sites on odorant receptor promoter sequences. Similar binding sites were also found on a number of enhancers that regulate in cis their transcription, but have been proposed to form interchromosomal networks. Odorant receptor gene choice seems to occur via the local removal of strongly repressive epigenetic markings, put in place during the maturation of the sensory neuron on each odorant receptor locus. Here we review the fast-changing state of art for the study of regulatory features for odorant receptor genes.

Keywords: allelic exclusion, element, enhancer, epigenetics, gene expression, odorant receptor gene choice, promoter, TFBS

\section{INTRODUCTION}

Many animals rely strongly on olfaction in order to get information about their surroundings, look for food, escape from predators, find a mate and communicate with each other. The transcriptional regulation of odorant receptor genes - comprising in mice $\sim 1100$ intact members (Buck and Axel, 1991; Niimura et al., 2014) - displays an almost unique feature: from the whole set, a single odorant receptor gene is monoallelicaly expressed in a single sensory neuron. This singularity is driven by mostly uncharacterized molecular dynamics, collectively termed odorant receptor gene choice, which seem to occur via local removal of strongly repressive epigenetic marks put in place on each odorant receptor locus during the maturation of the sensory neuron.

The scientific community has tried to identify sequences that regulate the expression of odorant receptor genes within their loci, which normally contain groups of related genes tightly arranged in genomic clusters (Sullivan et al., 1996; Niimura et al., 2014). Several studies identified transcription factor binding sites (TFBSs) on odorant receptor promoter sequences. Similar binding sites were also found on a number of enhancers located in proximity to odorant receptor genes. Those enhancers regulate in cis their transcription, and seem to form interchromosomal networks. 
A solid amount of evidences shows that odorant receptors are not only involved in odor detection (Buck and Axel, 1991), but also in neuronal maturation (Lyons et al., 2013), axonal sorting (Mombaerts et al., 1996; Wang et al., 1998; Vassalli et al., 2002) and neuronal longevity (Santoro and Dulac, 2012). However, their peculiar gene expression and how it is achieved still represent a fundamental open question.

\section{THE MOUSE OLFACTORY SYSTEM}

In mouse the task of sensing a vast range of molecules is run by the main and the accessory olfactory systems. The main olfactory system includes the main olfactory epithelium (MOE), which lines the turbinates in the posterior nasal cavity, and the main olfactory bulb (MOB) in the brain. The MOE is a neurogenic pseudostratified epithelium, which houses basal cells, supporting cells, Bowman's glands, and olfactory sensory neurons (OSNs); these are responsible for the detection of odorants and other ethologically important molecules. OSNs are bipolar neurons with an apical dendrite ending in a knob from which specialized cilia protrude into the mucus of the nasal cavity (Mendoza, 1993; for detailed reviews see also Breer et al., 2006; Tirindelli et al., 2009).

Primary transduction of odors takes place in the cilia, where the chemosensory receptors, either odorant (ORs) or trace amine-associated receptors (TAARs) are expressed (Buck and Axel, 1991; Liberles and Buck, 2006). These are G protein-coupled receptors (GPCRs) whose signals activate the transduction cascade and influence epigenetic gene regulation. ORs can be phylogenetically divided in two subfamilies: class I, comprising $\sim 125$ fish-like intact OR genes, and class II, including $\sim 1000$ intact OR genes specific for mammals (Niimura et al., 2014). OSNs express monogenically and monoallelicaly a single OR gene from the whole genomic repertoire (Ngai et al., 1993a,b; Chess et al., 1994), a feature known as one neuron-one receptor rule. However, as recently reported by Greer et al. (2016), a subset of OSNs localized in the recesses of the olfactory epithelium seems to escape this general rule: each OSNs of the necklace subsystem expresses multiple MS4As genes, coding for four-transmembrane chemoreceptors; through a yet unknown signaling path, they are mainly involved in detection of pheromones and others ethologically relevant ligands.

Axons from OSNs expressing the same OR gene, after crossing the cribriform plate, bundle together converging on the same location, referred to as a glomeruli, in a few stereotypic domains of the MOB (Le Gros Clark and Turner Warwick, 1946; Ressler et al., 1994; Vassar et al., 1994; Mombaerts et al., 1996). Axonal wiring is a process in which the sensory receptor itself has a fundamental role (Mombaerts et al., 1996; Wang et al., 1998; Vassalli et al., 2002; Movahedi et al., 2016).

The accessory olfactory system includes the vomeronasal organ of Jacobson and its projections to the accessory olfactory bulb, located in a posterior dorsal region of the MOB (McCotter, 1912; Breer et al., 2006), and other olfactory compartments: the septal organ of Masera, sited close to the nasal septum, that sends axonal projections to a subset of glomeruli in the
MOB; the Grueneberg ganglion, in the anterodorsal region of the nasal cavity, that sends projections to a subpopulation of the necklace glomeruli in the MOB. Neurons found in septal organ and Grueneberg ganglion epithelia are generally called OSNs, although some of those, as well as the already mentioned necklace OSNs, display some peculiarities (Fleischer and Breer, 2010; Greer et al., 2016).

The vomeronasal organ is a blind tubular structure located at the base of the nasal septum and mainly deputed to pheromone detection. It presents a non-sensory region and a sensory pseudostratified epithelium hosting vomeronasal sensory neurons (VSNs), basal stem cells, and supporting cells (Halpern, 1987; Døving and Trotier, 1998; Ishii and Mombaerts, 2008). VSNs are bipolar neurons with a single dendrite ending in a knob that exposes microvilli to the vomeronasal lumen. They are divided in two main subpopulations distributed on an apical and a basal layer and having as receptors members of two different families of vomeronasal GPCRs. Apical VSNs coexpress G-protein subunit $G_{\alpha i 2}$ and receptor genes of the family V1R, which includes $\sim 150$ intact genes (out of 300 genes) divided in 12 clades (Dulac and Axel, 1995; Jia and Halpern, 1996). Genes belonging to the same subfamily are organized in clusters (Herrada and Dulac, 1997; Matsunami and Buck, 1997; Ryba and Tirindelli, 1997; Rodriguez et al., 2002; Zhang et al., 2004) and they have monogenic and monoallelic expression (Dulac and Axel, 1995; Rodriguez et al., 1999; Roppolo et al., 2007). Basal VSNs coexpress $G$-protein subunit $G_{\alpha_{0}}$ and receptor genes of the family V2R, which includes $\sim 120$ intact genes (out of 280) divided in the subfamilies $\mathrm{A}, \mathrm{B}$, and $\mathrm{D}$, comprising most of the intact V2Rs gene repertoire, and the subfamily C (seven genes). V2R sensory neurons express a single, apparently stochastically chosen, member of subfamily $\mathrm{C}$ plus one or more selected member of subfamilies A, B, or D (Herrada and Dulac, 1997; Matsunami and Buck, 1997; Ryba and Tirindelli, 1997; Martini et al., 2001; Silvotti et al., 2007; Ishii and Mombaerts, 2011). A subset of these neurons may also express non-classical major histocompatibility complex (MHC) $16 \mathrm{H} 2-\mathrm{Mv}$ genes (Ishii and Mombaerts, 2008; Leinders-Zufall et al., 2009). Although most of the regulatory features of V1R and V2R genes are still not well known, Enomoto et al. (2011) reported that transcription factor bcl11b has an important role in regulating the fate choice between the V1R and V2R types of VSNs.

A small subset of VSNs, mostly in the apical neurons, monogenically expresses genes coding for formyl peptide receptors (FPRs), GPCRs that are mainly involved in microbial and viral peptide detection (Rivière et al., 2009; Bufe et al., 2015).

\section{GENOMIC ORGANIZATION OF ODORANT RECEPTOR GENES AND OLFACTORY CODING}

Olfactory information is encoded by thousands OSNs, each of which can bind different molecules with different affinity in a combinatorial fashion (Nara et al., 2011; Jiang et al., 2015) that amplifies the odorant discrimination possibilities of the already huge OR repertoire. 
The OR gene family is spread across all genome: class I OR genes are in a single cluster on chromosome 7; class II OR genes are scattered on all chromosomes except the 18 and Y, and arranged in clusters distributed in $\sim 50$ loci, which have a usual intergenic distance of 19-45 kb (Young et al., 2002; Zhang et al., 2007; Clowney et al., 2012), and few more solitary genes distant more than $1 \mathrm{Mb}$ upstream and downstream from the start and end of their transcripts (Zhang and Firestein, 2002; Godfrey et al., 2004; Malnic et al., 2004; Degl'Innocenti et al., 2016). OR genes are encoded by single exon $\sim 1 \mathrm{~kb}$ long and present conserved amino acid motifs characteristic of their family (Lane et al., 2001; Ibarra-Soria et al., 2014; Kanageswaran et al., 2015; Saraiva et al., 2015). As said, the single OR allele expressed in a single OSN determines also its identity, and influence the OSN's axonal wiring to specific glomeruli in the bulb, resulting in a stereotyped sensory map that depends from not yet known information provided by the OR. Knowing how odorant receptor gene choice works is therefore pivotal to understand also the logic behind the olfactory input integration.

To explain OR gene choice, several evidences point towards molecular mechanisms that lead to the random choice of only one among several OR promoters, possibly through epigenetic dynamics (Chess et al., 1994; Lomvardas et al., 2006; Clowney et al., 2012). Instead, the possibility of gene rearrangements for OR loci in the OSN lineage has been excluded, at least for the locus of model OR gene $M 71$. In fact, cloning a mouse from the nucleus of an M71-expressing OSN resets OR gene choice in favor of $M 71$, and results in specimens with a normal OR gene expression (Eggan et al., 2004; Li et al., 2004).

\section{CIS-REGULATING SEQUENCES FOR ODORANT RECEPTOR GENES}

\section{Odorant Receptor Gene Promoters}

OR gene promoters are AT-rich sequences usually lacking a TATA-box, although some do have one (Clowney et al., 2011; Young et al., 2011; Plessy et al., 2012). When present, however, their positions do not closely correlate with the transcription start site of the gene. For many OR genes, initiation of transcription may adhere to the so-called rule of genomic contrast: mRNA polymerization would be caused not by specific increase in AT content but by a sudden local variation of it (cf. Clowney et al., 2011). OR promoters typically feature TFBSs for homeodomain and for olfactory/early B transcription factors (Wang et al., 1997; Vassalli et al., 2002; Young et al., 2011; Plessy et al., 2012), whose presence was in some cases confirmed in vivo (Rothman et al., 2005; Vassalli et al., 2011). Along with them, other TFBSs were found on their sequences, e.g., for MEF2A (Plessy et al., 2012). TFBSs are considered major players in defining zonality of OR gene expression: OSNs found within a given zone, i.e., MOE-subdomain with typical transcriptome, choose stochastically their OR allele out of a subset of the whole genomic repertoire. Non-chosen OR promoters are epigenetically silenced by $\mathrm{H} 3 \mathrm{~K} 9 \mathrm{me} 3$ and H4K20me3 marks (Magklara et al., 2011). From functional studies, minimal promoters appear to be quite short ( $\sim 300 \mathrm{bp}$; Vassalli et al., 2011), and sequences of similar length have proven to be capable to drive punctate, stochastic expression of OR transgenes in the MOE (Vassalli et al., 2002, 2011; Rothman et al., 2005).

\section{Odorant Receptor Elements}

Elements for OR genes are non-genic regulatory sequences traditionally classified as enhancers, although their very nature as facilitators of transcription is debated: it has been proposed that elements differ from typical enhancers in the sense that they control the probability of a given OR gene to be chosen, rather than merely increasing the amount of transcript per cell for all the genes they regulate (Khan et al., 2011; Vassalli et al., 2011). Elements are invariably found within, or in proximity to, OR loci (Khan et al., 2011; Markenscoff-Papadimitriou et al., 2014). Their sequences contain, similarly to OR promoters, homeodomain and olfactory/early B TFBSs, plus additional TFBSs like those for Foxj2, Cdx, C/EBPgamma, Bptf (Markenscoff-Papadimitriou et al., 2014). To date, a total of 14 enhancers are though to regulate OR gene expression in the mouse, three of them being robustly confirmed in vivo; these are called $\mathrm{H}, \mathrm{P}$, and Lipsi (Nishizumi et al., 2007; Bozza et al., 2009; Khan et al., 2011; Markenscoff-Papadimitriou et al., 2014). It was realized long ago that elements might have been somehow involved in OR gene choice (Serizawa et al., 2000, 2003; Lewcock and Reed, 2004; Shykind et al., 2004), but no clear mechanism has been found yet: elements regulate the expression of OR genes in their in cis proximities, although Markenscoff-Papadimitriou et al. (2014) has suggested they may possess in trans activity with high degree of redundancy. Table 1 summarizes DNA regulatory features for OR genes.

\section{ODORANT RECEPTOR GENE CHOICE: REPRESSIVE MECHANISMS}

The organization of the nucleus in OSNs plays a role in the regulation of $\mathrm{OR}$ gene expression. Instead of being at the nuclear periphery, as in typical eukaryotic cells, constitutive heterochromatin is mainly located in central nuclear region (Solovei et al., 2009; Clowney et al., 2012; Armelin-Correa et al., 2014a). Indeed, in the early differentiation steps of OSNs, long before OR gene choice takes place, robust silencing and packing occurs on OR loci. Cytogenetically OR gene loci (and their enhancers) become aggregated in a small number of nuclear locations including arrangements named foci, tridimensional chromatin structures characterized by the repressive epigenetic marks $\mathrm{H} 3 \mathrm{~K} 9 \mathrm{me} 3$ and H4K20me3, typical of constitutive pericentromeric and subtelomeric chromatin (Magklara et al., 2011). These marks will be removed later on from a single $\mathrm{OR}$ allele, ensuring monogenic and monoallelic expression (Clowney et al., 2012).

Not all OR gene loci are confined in foci: constitutive heterochromatin is surrounded by more dynamic facultative heterochromatin, and alleles of the same OR tend to reside on 
TABLE 1 | DNA regulatory features for odorant receptor genes.

\begin{tabular}{ll}
\hline Regulatory feature & Location \\
\hline $\begin{array}{l}\text { Enriched presence of 8-oxodG (oxidative } \\
\text { damage) }\end{array}$ & Chosen OR allele \\
$\begin{array}{l}\text { Enrichment for DNase I hypersensitive } \\
\text { sites }\end{array}$ & H and P elements (also in OSNs not expressing an \\
Hist2h2be (H2BE) & OR gene found in cis with them), other elements \\
replication-independent histone variant & Position (e) among HeB-encoding genes, histone \\
H3K27ac epigenetic marks & cluster 2 \\
& H and P elements (also in OSNs not expressing an \\
H3K27me3 epigenetic marks & OR gene found in cis with them), other elements \\
H3K4me1 epigenetic marks & Silenced OR loci, element-flanking regions \\
H3K4me3 epigenetic marks & H and P elements (also in OSNs not expressing an \\
H3K79me3 epigenetic marks & OR gene found in cis with them) \\
H3K9me3 epigenetic marks & Chosen/euchromatic OR alleles \\
H4K20me3 epigenetic marks & \\
Homeodomain binding sites & Element-flanking regions \\
& Silenced OR loci \\
& Silenced OR loci \\
& \\
& OR promoters
\end{tabular}

Local variation in AT content associated with transcription start site

$\mathrm{O} / \mathrm{E}$ binding sites

O/E binding sites
OR promoters

Elements

OR promoters

\section{Reference}

Lyons et al., 2013.

Markenscoff-Papadimitriou et al., 2014.

Santoro and Dulac, 2012.

Markenscoff-Papadimitriou et al., 2014.

Magklara et al., 2011; Armelin-Correa et al., 2014a,b; Markenscoff-Papadimitriou et al., 2014.

Colquitt et al., 2014; Markenscoff-Papadimitriou et al., 2014.

Magklara et al., 2011; Clowney et al., 2012; Armelin-Correa et al., 2014a; Tian et al., 2016.

Markenscoff-Papadimitriou et al., 2014.

Clowney et al., 2011; Magklara et al., 2011; Clowney et al., 2012; Lyons et al., 2013; Armelin-Correa et al., 2014a.

Clowney et al., 2011; Magklara et al., 2011; Clowney et al., 2012; Armelin-Correa et al., 2014a.

Nishizumi et al., 2007; Bozza et al., 2009; Vassalli et al., 2011; Markenscoff-Papadimitriou et al., 2014.

Vassalli et al., 2002, 2011; Hoppe et al., 2003, 2006; Hirota and Mombaerts, 2004; Rothman et al., 2005; Hirota et al., 2007; Clowney et al., 2011; Young et al., 2011; Plessy et al., 2012; Degl'Innocenti et al., 2016; Zhang et al., 2016.

Clowney et al., 2011; Magklara et al., 2011.

Nishizumi et al., 2007; Bozza et al., 2009; Vassalli et al., 2011; Markenscoff-Papadimitriou et al., 2014

Wang et al., 1997; Vassalli et al., 2002, 2011; Hoppe et al., 2003, 2006; Hirota and Mombaerts, 2004; Rothman et al., 2005; Michaloski et al., 2006; Clowney et al., 2011; Michaloski et al., 2011; Young et al., 2011; Plessy et al., 2012.

Markenscoff-Papadimitriou et al., 2014.

Clowney et al., 2011; Michaloski et al., 2011; Young et al., 2011; Plessy et al., 2012

Other transcription factor binding sites
(Atf5, Bptf, Cdx, C/EBPgamma, Foxj2)

Other transcription factor binding sites (MEF2A, TBP, and transcriptional repressors resembling $\mathrm{RP58}$ )

Elements

(some) OR promoters

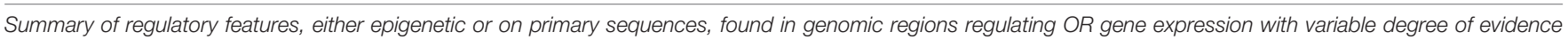

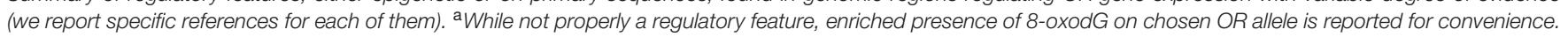

different compartments, one within constitutive heterochromatin and the other in facultative heterochromatin. In fact, as for any monoallelicaly expressed gene family, homologous alleles of OR genes are replicated asynchronously (Chess et al., 1994). Consistent with these observations, immunofluorescence staining of the olfactory epithelium for H3K27me3 - a mark for facultative heterochromatin - indicates that it is present in the nuclei of OSNs (Armelin-Correa et al., 2014a). However, no clear evidence of $\mathrm{H} 3 \mathrm{~K} 27 \mathrm{me} 3$ marks on OR genes has been found yet (Magklara et al., 2011), although ArmelinCorrea et al. (2014a) report H3K27me3 markings being required for asymmetric replication of OR genes in embryonic stem cells.

Recent studies show that early developing OSNs can weakly express multiple OR genes, while during subsequent stages of development the expression of one single OR gene overtakes and the other OR loci get silenced (Hanchate et al., 2015; Saraiva et al., 2015; Tan et al., 2015; Scholz et al., 2016). To explain this transition, Hanchate et al. (2015) proposed a winner takes all-model where one of the initially expressed OR genes becomes dominant, capturing limiting factors required for high expression level. Alternatively, the high expression of one OR gene would occur independently of other earlier expressed genes. Hanchate et al. (2015) also suggest a regional bias in OR gene choice: early co-expressed OR genes, although sitting at multiple chromosomal locations, are expressed in neurons located in the same region of MOE.

Immature OSNs expressing an OR gene can still switch to another OR gene in a loop-process that continues until a functional OR gene is expressed and elicits a feedback signal that stops the cycle and stabilizes the choice (Serizawa et al., 2003; 
Lewcock and Reed, 2004; Shykind et al., 2004). In post-mitotic OSNs, a single OR gene - chosen in a stochastic, yet elusive event - escapes foci and gets repositioned in a nearby nuclear area (Clowney et al., 2012). According to Lyons et al. (2013) a derepressor with limited availability, either in space or time, would act together with the histone lysine demethylase 1 (Lsd1), transiently expressed at the core time window of OR gene choice. This event is associated with an epigenetic switch from $\mathrm{H} 3 \mathrm{~K} 9 \mathrm{me} 3$ to $\mathrm{H} 3 \mathrm{~K} 4 \mathrm{me} 3$ for the chosen $\mathrm{OR}$ allele, which perhaps interacts with an interchromosomal complex of elements (Magklara et al., 2011; Lyons et al., 2013; Markenscoff-Papadimitriou et al., 2014). Currently, it is unclear whether H3K27 demethylases may have a role in the process too (Armelin-Correa et al., 2014a).

The expression of an intact OR gene activates the unfolded protein response, which eventually leads to the production of adenylate cyclase 3 (Adcy3); Adcy3 represses Lsd1 and promotes neuronal maturation, locking OR gene choice. If the OR gene is nonfunctional and fails to elicit Adcy3-mediated feedback, Lsd1 retains its activity: it might re-heterochromatize the opened locus, or alternatively it may open another one. This process of choice (Figure 1) would continue until an OR gene succeeds in being stably expressed (Dalton et al., 2013).

Whereas developmental expression seems to be independent from odorant receptor-induced neuronal activity (Hanchate et al., 2015), Ferreira et al. (2014) have shown in zebrafish that the $\beta \gamma$ subunit of the olfactory $G$ protein, released when an OR binds its ligand, has a direct impact on the methylation state of silenced OR loci, thus linking receptor activity to the epigenetic regulation behind the single OR gene choice mechanism.

More recently Zhang et al. (2016) have shown that the homeodomain transcription factor Lhx2 influences OR expression frequencies in immature and mature OSNs, and it is necessary for driving OR expression but not for the OR singularity, although they do not exclude an indirect role in OR gene choice.
A

Silencing

- Element

- "Chosen"-OR Gene

$\triangle$ Foci

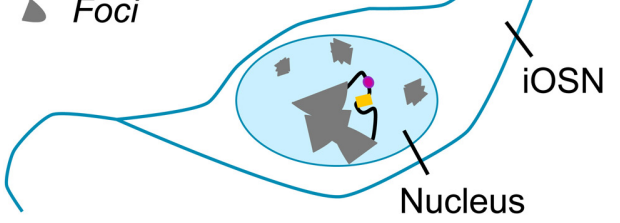

C

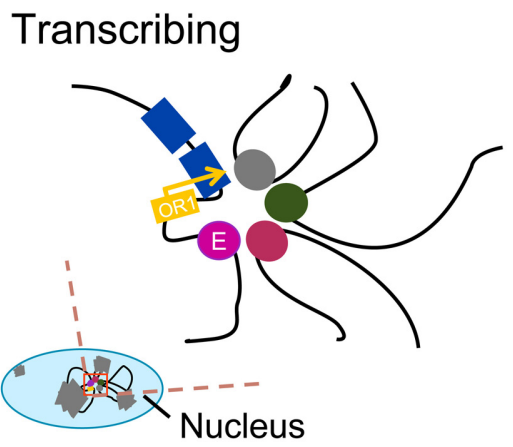

B

De-repressing

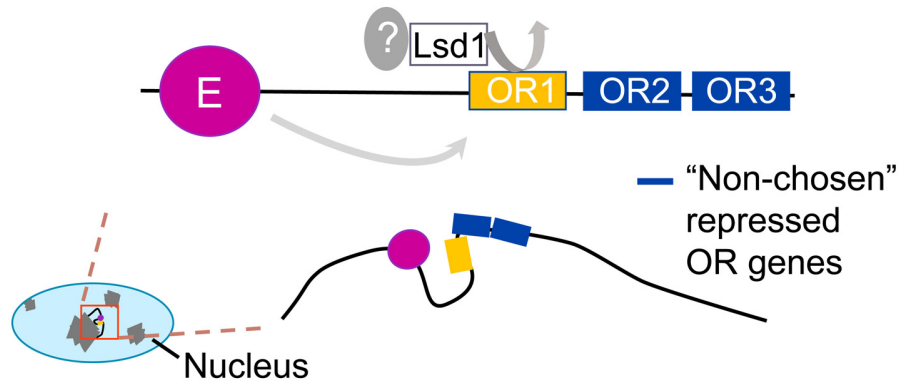

D

Eliciting feedback

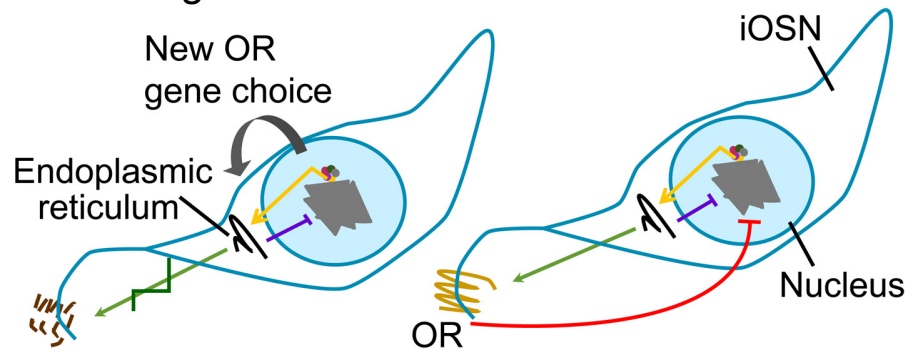

Non-functional OR

Stabilizing OR gene choice

FIGURE 1 | Main steps of odorant receptor gene choice. Gray areas represent foci; black filament represents euchromatin; colored circles represent elements; yellow box represents the single -"chosen" odorant receptor (OR) allele; blue boxes represent nearby OR genes with repressive marks. (A) Silencing: in the nucleus of maturing olfactory sensory neuron (iOSN), OR gene loci are heterochromatized; one locus undergoes an epigenetic change. (B) De-repressing: local variation in epigenetic state on OR heterochromatin (magnified shadowed red-stroked box) is initiated by an unknown derepressor, which cooperates with Lsd1 and perhaps with H3K27 demethylases in the random opening of one OR allele only; an element in the same OR locus interacts with the OR gene via DNA-looping; nearby OR genes keep their repressive marks. (C) Transcribing: on the euchromatic OR allele, an interchromosomal complex of elements drives robust expression of the gene. (D) Eliciting feedback: if massive protein production within the endoplasmic reticulum is achieved, unfolded protein response is triggered; this causes

Adcy3-mediated block on Lsd1, resulting in cell inability to unpack silenced OR loci and to re-close the euchromatized allele (purple line); left, if the "chosen-OR" is a pseudogene the process is repeated with a new OR-choice; right, if a functional OR protein is produced (green arrow), its activity leads to the release of the $\beta \gamma$ subunit of the G protein, which further prevents other OR alleles to escape foci (red line); therefore, in order to stabilize OR gene choice, the process induces odorant sensory neuron (OSN) maturation. 


\section{CONCLUDING REMARKS}

Overall, OR genes seem to adopt a lock-and-key strategy for expression; all loci are initially epigenetically silenced, then a limiting factor randomly opens a single allele that later on stabilizes its own transcription through complex feedback mechanisms. Aside from the olfactory system, others examples of way to increase cellular diversity among similar cell types are provided by immune system (Hozumi and Tonegawa, 1976; Jaeger et al., 2013; Magklara and Lomvardas, 2013), and protocadherins (Lefebvre et al., 2012). Several transcriptional characteristics seem to recur in other clustered gene families, such as globins and homeobox genes, which also display oligogenic expression. However, whilst globins (Drescher and Künzer, 1954; Huehns et al., 1964; Groudine et al., 1983) and homeobox (Gaunt et al., 1988; Duboule and Dollé, 1989; Dressler and Gruss, 1989; Graham et al., 1989) genes are serially expressed according to their chromosomal location, OR gene family requires more complex regulation. What are the molecular mechanisms that

\section{REFERENCES}

Armelin-Correa, L. M., Gutiyama, L. M., Brandt, D. Y., and Malnic, B. (2014a). Nuclear compartmentalization of odorant receptor genes. Proc. Natl. Acad. Sci. U.S.A. 111, 2782-2787. doi: 10.1073/pnas.1317036111

Armelin-Correa, L. M., Nagai, M. H., Leme Silva, A. G., and Malnic, B. (2014b). Nuclear architecture and gene silencing in olfactory sensory neurons. Bioarchitecture 4, 160-163. doi: 10.4161/19490992.2014.982934

Bozza, T., Vassalli, A., Fuss, S., Zhang, J. J., Weiland, B., and Pacifico, R. (2009). Mapping of class I and class II odorant receptors to glomerular domains by two distinct types of olfactory sensory neurons in the mouse. Neuron 61, 220-233. doi: 10.1016/j.neuron.2008.11.010

Breer, H., Fleischer, J., and Strotmann, J. (2006). The sense of smell: multiple olfactory subsystems. Cell. Mol. Life Sci. 63, 1465-1475. doi: 10.1007/s00018006-6108-5

Buck, L., and Axel, R. (1991). A novel multigene family may encode odorant receptors: a molecular basis for odor recognition. Cell 65, 175-187. doi: 10.1016/ 0092-8674(91)90418-X

Bufe, B., Schumann, T., Kappl, R., Bogeski, I., Kummerow, C., Podgorska, M., et al. (2015). Recognition of bacterial signal peptides by mammalian formyl peptide receptors. J. Biol. Chem. 290, 7369-7387. doi: 10.1074/jbc.M114. 626747

Chess, A., Simon, I., Cedar, H., and Axel, R. (1994). Allelic inactivation regulates olfactory receptor gene expression. Cell 78, 823-834. doi: 10.1016/S00928674(94)90562-2

Clowney, E. J., Legros, M. A., Mosley, C. P., Clowney, F. G., MarkenskoffPapadimitriou, E. C., Myllys, M., et al. (2012). Nuclear aggregation of olfactory receptor genes governs their monogenic expression. Cell 151, 724-737. doi: 10.1016/j.cell.2012.09.043

Clowney, E. J., Magklara, A., Colquitt, B. M., Pathak, N., Lane, R. P., and Lomvardas, S. (2011). High-throughput mapping of the promoters of the mouse olfactory receptor genes reveals a new type of mammalian promoter and provides insight into olfactory teceptor gene regulation. Genome Res. 21, 1249-1259. doi: 10.1101/gr.120162.110

Colquitt, B. M., Markenscoff-Papadimitriou, E., Duffié, R., and Lomvardas, S. (2014). Dnmt3a regulates global gene expression in olfactory sensory neurons and enables odorant-induced transcription. Neuron 83, 823-838. doi: 10.1016/ j.neuron.2014.07.013

Dalton, R. P., Lyons, D. B., and Lomvardas, S. (2013). Co-opting the unfolded protein response to elicit olfactory receptor feedback. Cell 155, 321-332. doi: 10.1016/j.cell.2013.09.033

Degl'Innocenti, A., Parrilla, M., Harr, B., and Teschke, M. (2016). The mouse solitary odorant receptor gene promoters as models for the study of odorant lead to the OR gene expression? How is the OSN transition to a single highly expressed OR gene regulated? How does the nuclear architecture influence this process? What is the missing link between OR gene expression and the mature OSN identity? These are only few of the fundamental open questions still tickling the olfaction field.

\section{AUTHOR CONTRIBUTIONS}

ADI drafted an early version of the manuscript, AD critically revised it. ADI and AD wrote the manuscript. All authors read and accepted the final version.

\section{FUNDING}

Funding was provided by the Max Planck Society and the Max Planck Institute of Biophysics.

receptor gene choice. PLOS ONE 11:e0144698. doi: 10.1371/journal.pone. 0144698

Døving, K. B., and Trotier, D. (1998). Structure and function of the vomeronasal organ. J. Exp. Biol. 201(Pt 21), 2913-2925.

Drescher, H., and Künzer, W. (1954). Der Blutfarbstoff des menschlichen Feten. Klin. Wochenschr. 32, 92. doi: 10.1007/bf01493536

Dressler, G. R., and Gruss, P. (1989). Anterior boundaries of hox gene expression in mesoderm-derived structures correlate with the linear gene order along the chromosome. Differentiation 41, 193-201. doi: 10.1111/j.1432-0436.1989. tb00747.x

Duboule, D., and Dollé, P. (1989). The structural and functional organization of the murine HOX gene family resembles that of drosophila homeotic genes. $E M B O$ J. 8, 1497-1505.

Dulac, C., and Axel, R. (1995). A novel family of genes encoding putative pheromone receptors in mammals. Cell 83, 195-206. doi: 10.1016/00928674(95)90161-2

Eggan, K., Baldwin, K., Tackett, M., Osborne, J., Gogos, J., Chess, A., et al. (2004). Mice cloned from olfactory sensory neurons. Nature 428, 44-49. doi: 10.1038/ nature 02375

Enomoto, T., Ohomoto, M., Iwata, T., Uno, T., Saitou, M., Yamaguchi, T., et al. (2011). Bcl11b/Ctip2 controls the differentiation of vomeronasal sensory neurons in mice. J. Neurosci. 31, 10159-10173. doi: 10.1523/JNEUROSCI.124511.2011

Ferreira, T., Wilson, S. R., Choi, Y. G., Risso, D., Dudoit, S., Speed, T. P., et al. (2014). Silencing of odorant receptor genes by $\mathrm{G}$ protein $\beta \gamma$ signaling ensures the expression of one odorant receptor per olfactory sensory neuron. Neuron 81, 847-859. doi: 10.1016/j.neuron.2014.01.001

Fleischer, J., and Breer, H. (2010). The grueneberg ganglion: a novel sensory system in the nose. Histol. Histopathol. 25, 909-915.

Gaunt, S. J., Sharpe, P. T., and Duboule, D. (1988). Spatially restricted domains of homeo-gene transcripts in mouse embryos: relation to a segmented body plan. Development 104(Suppl.), 169-179.

Godfrey, P. A., Malnic, B., and Buck, L. B. (2004). The mouse olfactory receptor gene family. Proc. Natl. Acad. Sci. U.S.A. 17, 2156-2161. doi: 10.1073/pnas. 0308051100

Graham, A., Papalopulu, N., and Krumlauf, R. (1989). The murine and drosophila homeobox gene complexes have common features of organization and expression. Cell 57, 367-378. doi: 10.1016/0092-8674(89)90912-4

Greer, P. L., Bear, D. M., Lassance, J., Bloom, M. L., Tsukahara, T., Pashkovski, S. L., et al. (2016). A family of non-GPCR chemosensors defines an alternative logic for mammalian olfaction. Cell 165, 1734-1748. doi: 10.1016/j.cell.2016.05.001

Groudine, M., Kohwi-Shigematsu, T., Gelinas, R., Stamatoyannopoulos, G., and Papayannopoulou, T. (1983). Human fetal to adult hemoglobin switching: 
changes in chromatin structure of the beta-globin gene locus. Proc. Natl. Acad. Sci. U.S.A. 80, 7551-7555. doi: 10.1073/pnas. 80.24 .7551

Halpern, M. (1987). The organization and the function of the vomeronasal system. Ann. Rev. Neurosci. 10, 325-362. doi: 10.1146/annurev.ne.10.030187.001545

Hanchate, N. K., Kondoh, K., Lu, Z., Kuang, D., Ye, X., Qiu, X., et al. (2015). Single-cell transcriptomics reveals receptor transformations during olfactory neurogenesis. Science 3, 123-128. doi: 10.1126/science.aad2456

Herrada, G., and Dulac, C. (1997). A novel family of putative pheromone receptors in mammals with a topographically organized and sexually dimorphic distribution. Cell 90, 763-773. doi: 10.1016/S0092-8674(00)80536-X

Hirota, J., and Mombaerts, P. (2004). The LIM-homeodomain protein Lhx2 is required for complete development of mouse olfactory sensory neurons. Proc. Natl. Acad. Sci. U.S.A. 101, 8751-8755. doi: 10.1073/pnas.0400940101

Hirota, J., Omura, M., and Mombaerts, P. (2007). Differential impact of Lhx2 deficiency on expression of class I and class II odorant receptor genes in mouse. Mol. Cell. Neurosci. 34, 679-688. doi: 10.1016/j.mcn.2007.01.014

Hoppe, R., Breer, H., and Strotmann, J. (2006). Promoter motifs of olfactory receptor genes expressed in distinct topographic patterns. Genomics 87, 711723. doi: 10.1016/j.ygeno.2006.02.005

Hoppe, R., Frank, H., Breer, H., and Strotmann, J. (2003). The clustered olfactory receptor gene family 262: genomic organization, promotor elements, and interacting transcription factors. Genome Res. 13, 2674-2685. doi: 10.1101/gr. 1372203

Hozumi, N., and Tonegawa, S. (1976). Evidence for somatic rearrangement of immunoglobulin genes coding for variable and constant regions. Proc. Natl. Acad. Sci. U.S.A. 73, 3628-3632. doi: 10.1073/pnas.73.10.3628

Huehns, E. R., Dance, N., Beaven, G. H., Keil, J. V., Hecht, F., and Motulsky, A. G. (1964). Human embryonic haemoglobins. Nature 14, 1095-1097. doi: $10.1038 / 2011095 \mathrm{a} 0$

Ibarra-Soria, X., Levitin, M. O., Saraiva, L. R., and Logan, D. W. (2014). The olfactory transcriptomes of mice. PLoS Genet. 10:e1004593. doi: 10.1371/ journal.pgen.1004593

Ishii, T., and Mombaerts, P. (2008). Expression of nonclassical class I major histocompatibility genes defines a tripartite organization of the mouse vomeronasal system. J. Neurosci. 28, 2332-2341. doi: 10.1523/JNEUROSCI. 4807-07.2008

Ishii, T., and Mombaerts, P. (2011). Coordinated coexpression of two vomeronasal receptor V2R genes per neuron in the mouse. Mol. Cell. Neurosci. 46, 397-408. doi: 10.1016/j.mcn.2010.11.002

Jaeger, S., Fernandez, B., and Ferrier, P. (2013). Epigenetic aspects of lymphocyte antigen receptor gene rearrangement or 'when stochasticity completes randomness'. Immunology 139, 141-150. doi: 10.1111/imm.12057

Jia, C., and Halpern, M. (1996). Subclasses of vomeronasal receptor neurons: differential expression of $\mathrm{G}$ proteins ( $\mathrm{Gi}$ alpha 2 and $\mathrm{G}(\mathrm{O}$ alpha $)$ ) and segregated projections to the accessory olfactory bulb. Brain Res. 719, 117-128. doi: 10. 1016/0006-8993(96)00110-2

Jiang, Y., Gong, N. N., Hu, X. S., Ni, M. J., Pasi, R., and Matsunami, H. (2015). Molecular profiling of activated olfactory neurons identifies odorant receptors for odors in vivo. Nat. Neurosci. 18, 1446-1454. doi: 10.1038/nn.4104

Kanageswaran, N., Demond, M., Nagel, M., Schreiner, B. S., Baumgart, S., Scholz, P., et al. (2015). Deep sequencing of the murine olfactory receptor neuron transcriptome. PLOS ONE 10:e0113170. doi: 10.1371/journal.pone. 0113170

Khan, M., Vaes, E., and Mombaerts, P. (2011). Regulation of the probability of mouse odorant receptor gene choice. Cell 147, 907-921. doi: 10.1016/j.cell.2011. 09.049

Lane, R. P., Cutforth, T., Young, J., Athanasiou, M., Friedman, C., Rowen, L., et al. (2001). Genomic analysis of ortholo- gous mouse and human olfactory receptor loci. Proc. Natl. Acad. Sci. U.S.A. 98, 7390-7395. doi: 10.1073/pnas.131215398

Le Gros Clark, W. E., and Turner Warwick, R. T. (1946). The pattern of olfactory innervation. J. Neurol. Neurosurg. Psychiatry 9, 101-111. doi: 10.1136/jnnp. 9.3.101

Lefebvre, J. L., Kostadinov, D., Chen, W. V., Maniatis, T., and Sanes, J. R. (2012). Protocadherins mediate dendritic self-avoidance in the mammalian nervous system. Nature 488, 517-521. doi: 10.1038/nature11305

Leinders-Zufall, T., Ishii, T., Mombaerts, P., Zufall, F., and Boehm, T. (2009). Structural requirements for the activation of vomeronasal sensory neurons by MHC peptides. Nat. Neurosci. 12, 1551-1558. doi: 10.1038/nn.2452
Lewcock, J. W., and Reed, R. R. (2004). A feedback mechanism regulates monoallelic odorant receptor expression. Proc. Natl. Acad. Sci. U.S.A. 101, 1069-1074. doi: 10.1073/pnas.0307986100

Li, J., Ishii, T., Feinstein, P., and Mombaerts, P. (2004). Odorant receptor gene choice is reset by nuclear transfer from mouse olfactory sensory neurons. Nature 428, 393-399. doi: 10.1038/nature02433

Liberles, S. D., and Buck, L. B. (2006). A second class of chemosensory receptors in the olfactory epithelium. Nature 442, 645-650. doi: 10.1038/nature05066

Lomvardas, S., Barnea, G., Pisapia, D. J., Mendelsohn, M., Kirkland, J., and Axel, R. (2006). Interchromosomal interactions and olfactory receptor choice. Cell 126, 403-413. doi: 10.1016/j.cell.2006.06.035

Lyons, D. B., Allen, W. E., Goh, T., Tsai, L., Barnea, G., and Lomvardas, S. (2013). An epigenetic trap stabilizes singular olfactory receptor expression. Cell 154, 325-336. doi: 10.1016/j.cell.2013.06.039

Magklara, A., and Lomvardas, S. (2013). Stochastic gene expression in mammals: lessons from olfaction. Trends Cell Biol. 23, 449-456. doi: 10.1016/j.tcb.2013. 04.005

Magklara, A., Yen, A., Colquitt, B. M., Clowney, E. J., Allen, W., MarkenscoffPapadimitriou, E., et al. (2011). An epigenetic signature for monoallelic olfactory receptor expression. Cell 145, 555-570. doi: 10.1016/j.cell.2011. 03.040

Malnic, B., Godfrey, P. A., and Buck, L. B. (2004). The human olfactory receptor gene family. Proc. Natl. Acad. Sci. U.S.A. 101, 2584-2589. doi: 10.1073/pnas. 0307882100

Markenscoff-Papadimitriou, E., Allen, W. E., Colquitt, B. M., Goh, T., Murphy, K. K., Monahan, K., et al. (2014). Enhancer interaction networks as a means for singular olfactory receptor expression. Cell 159, 543-557. doi: 10.1016/j.cell. 2014.09.033

Martini, S., Silvotti, L., Shirazi, A., Ryba, N. J., and Tirindelli, R. (2001). Coexpression of putative pheromone receptors in the sensory neurons of the vomeronasal organ. J. Neurosci. 21, 843-848.

Matsunami, H., and Buck, L. B. (1997). A multigene family encoding a diverse array of putative pheromone receptors in mammals. Cell 90, 775-784. doi: 10.1016/S0092-8674(00)80537-1

McCotter, R. E. (1912). The connection of the vomeronasal nerves with the accessory olfactory bulb in the opossum and other mammals. Anat. Rec. 6, 299-318. doi: 10.1002/ar.1090060802

Mendoza, A. S. (1993). Morphological studies on the rodent main and accessory olfactory systems: the regio olfactoria and vomeronasal organ. Ann. Anat. 175, 425-446. doi: 10.1016/S0940-9602(11)80110-X

Michaloski, J. S., Galante, P. A., Nagai, M. H., Armelin-Correa, L., Chien, M. S., Matsunami, H., et al. (2011). Common promoter elements in odorant and vomeronasal receptor genes. PLOS ONE 6:e29065. doi: 10.1371/journal.pone. 0029065

Michaloski, J. S., Galante, P. A. F., and Malnic, B. (2006). Identification of potential regulatory motifs in odorant receptor genes by analysis of promoter sequences. Genome Res. 16, 1091-1098. doi: 10.1101/gr.5185406

Mombaerts, P., Wang, F., Dulac, C., Chao, S. K., Nemes, A., Mendelsohn, M., et al. (1996). Visualizing an olfactory sensory map. Cell 87, 675-686. doi: 10.1016/ S0092-8674(00)81387-2

Movahedi, K., Grosmaitre, X., and Finestein, P. (2016). Odorant receptors can mediate axonal identity and gene choice via cAMP-indipendent mechanisms. Open Biol. 6, 160018. doi: 10.1098/rsob.160018

Nara, K., Saraiva, L. R., Ye, X., and Buck, L. B. (2011). A large-scale analysis of odor coding in the olfactory epithelium. J. Neurosci. 31, 9179-9191. doi: 10.1523/JNEUROSCI.1282-11.2011

Ngai, J., Chess, A., Dowling, M. M., Necles, N., Macagno, E. R., and Axel, R. (1993a). Coding of olfactory information: topography of odorant receptor expression in the catfish olfactory epithelium. Cell 72, 667-680.

Ngai, J., Dowling, M. M., Buck, L., Axel, R., and Chess, A. (1993b). The family of genes encoding odorant receptors in the channel catfish. Cell 72 , 657-666.

Niimura, Y., Matsui, A., and Touhara, K. (2014). Extreme expansion of the olfactory receptor gene repertoire in african elephants and evolutionary dynamics of orthologous gene groups in 13 placental mammals. Genome Res. 24, 1485-1496. doi: 10.1101/gr.169532.113

Nishizumi, H., Kumasaka, K., Inoue, N., Nakashima, A., and Sakano, H. (2007). Deletion of the core-H region in mice abolishes the expression of three proximal 
odorant receptor genes in cis. Proc. Natl. Acad. Sci. U.S.A. 104, 20067-20072. doi: 10.1073/pnas.0706544105

Plessy, C., Pascarella, G., Bertin, N., Akalin, A., Carrieri, C., Vassalli, A., et al. (2012). Promoter architecture of mouse olfactory receptor genes. Genome Res. 22, 486-497. doi: 10.1101/gr.126201.111

Ressler, K. J., Sullivan, S. L., and Buck, L. (1994). Information coding in the olfactory system: evidence for a stereotyped and highly organized epitope map in the olfactory bulb. Cell 79, 1245-1255. doi: 10.1016/0092-8674(94) 90015-9

Rivière, S., Challet, L., Fluegge, D., Spehr, M., and Rodriguez, I. (2009). Formil peptide receptor-like proteins are a novel family of vomeronasal chemosensors. Nature 459, 574-577. doi: 10.1038/nature08029

Rodriguez, I., Del Punta, K., Rothman, A., Ishii, T., and Mombaerts, P. (2002). Multiple new and isolated families within the mouse superfamily of V1r vomeronasal receptors. Nat. Neurosci. 5, 134-140. doi: 10.1038/ nn795

Rodriguez, I., Feinstein, P., and Mombaerts, P. (1999). Variable patterns of axonal projections of sensory neurons in the mouse vomeronasal system. Cell 97, 199-208. doi: 10.1016/S0092-8674(00)80730-8

Roppolo, D., Vollery, S., Kan, C. D., Lüscher, C., Broillet, M. C., and Rodriguez, I. (2007). Gene cluster lock after pheromone receptor gene choice. EMBO J. 26, 3423-3430. doi: 10.1038/sj.emboj.7601782

Rothman, A., Feinstein, P., Hirota, J., and Mombaerts, P. (2005). The promoter of the mouse odorant receptor gene M71. Mol. Cell. Neurosci. 28, 535-546. doi: $10.1016 /$ j.mcn.2004.11.006

Ryba, N. J., and Tirindelli, R. (1997). A new multigene family of putative pheromone receptors. Neuron 19, 371-379. doi: 10.1016/S0896-6273(00) 80946-0

Santoro, S. W., and Dulac, C. (2012). The activity-dependent histone variant H2BE modulates the life span of olfactory neurons. Elife 13:e00070. doi: 10.7554/eLife. 00070

Saraiva, L. R., Ibarra-Soria, X., Khan, M., Omura, M., Scialdone, A., Mombaerts, P., et al. (2015). Hierarchical deconstruction of mouse olfactory sensory neurons: from whole mucosa to single-cell RNA-seq. Sci. Rep. 5:18178. doi: 10.1038/ srep 18178

Scholz, P., Kalbe, B., Jansen, F., Altmueller, J., Becker, C., Mohrhardt, J., et al. (2016). Transcriptome analysis of murine olfactory sensory neurons during development using single cell RNA-Seq. Chem. Senses 41, 313-323. doi: 10. 1093/chemse/bjw003

Serizawa, S., Ishii, T., Nakatani, H., Tsuboi, A., Nagawa, F., Asano, M., et al. (2000). Mutually exclusive expression of odorant receptor transgenes. Nat. Neurosci. 3 , 687-693. doi: 10.1038/76641

Serizawa, S., Miyamichi, K., Nakatani, H., Suzuki, M., Saito, M., Yoshihara, Y., et al. (2003). Negative feedback regulation ensures the one receptor-one olfactory neuron rule in mouse. Science 302, 2088-2094. doi: 10.1126/science. 1089122

Shykind, B. M., Rohani, S. C., O'Donnell, S., Nemes, A., Mendelsohn, M., Sun, Y., et al. (2004). Gene switching and the stability of odorant receptor gene choice. Cell 117, 801-815. doi: 10.1016/j.cell.2004.05.015

Silvotti, L., Moiani, A., Gatti, R., and Tirindelli, R. (2007). Combinatorial coexpression of pheromone receptors, V2Rs. J. Neurochem. 103, 1753-1763. doi: 10.1111/j.1471-4159.2007.04877.x

Solovei, I., Kreysing, M., Lanctôt, C., Kösem, S., Peichl, L., Cremer, T., et al. (2009). Nuclear architecture of rod photoreceptor cells adapts to vision in mammalian evolution. Cell 137, 356-368. doi: 10.1016/j.cell.2009.01.052

Sullivan, S. L., Adamson, M. C., Ressler, K. J., Kozak, C. A., and Buck, L. B. (1996). The chromosomal distribution of mouse odorant receptor genes. Proc. Natl. Acad. Sci. U.S.A. 93, 884-888. doi: 10.1073/pnas.93.2.884
Tan, L., Li, Q., and Xie, S. (2015). Olfactory sensory neurons transiently express multiple olfactory receptors during development. Mol. Syst. Biol. 11:844. doi: $10.15252 / \mathrm{msb} .20156639$

Tian, X. J., Zhang, H., Sannerud, J., and Xing, J. (2016). Achieving diverse and monoallelic olfactory receptor selection through dual-objective optimization design. Proc. Natl. Acad. Sci. U.S.A. 113, E2889-E2898. doi: 10.1073/pnas. 1601722113

Tirindelli, R., Dibattista, M., Pifferi, S., and Menini, A. (2009). From pheromones to behavior. Physiol. Rev. 89, 921-956. doi: 10.1152/physrev.00037.2008

Vassalli, A., Feinstein, P., and Mombaerts, P. (2011). Homeodomain binding motifs modulate the probability of odorant receptor gene choice in transgenic mice. Mol. Cell. Neurosci. 46, 381-396. doi: 10.1016/j.mcn.2010.11.001

Vassalli, A., Rothman, A., Feinstein, P., Zapotocky, M., and Mombaerts, P. (2002). Minigenes impart odorant receptor-specific axon guidance in the olfactory bulb. Neuron 35, 681-696. doi: 10.1016/S0896-6273(02)00793-6

Vassar, R., Chao, S. K., Sitcheran, R., Nuñez, J. M., Vosshall, L. B., and Axel, R. (1994). Topographic organization of sensory projections to the olfactory bulb. Cell 79, 981-991. doi: 10.1016/0092-8674(94)90029-9

Wang, F., Nemes, A., Mendelsohn, M., and Axel, R. (1998). Odorant receptors govern the formation of a precise topographic map. Cell 93, 47-60. doi: 10.1016/ S0092-8674(00)81145-9

Wang, S. S., Tsai, R. Y., and Reed, R. R. (1997). The characterization of the Olf1/EBF-like HLH transcription factor family: implications in olfactory gene regulation and neuronal development. J. Neurosci. 17, 4149-4158.

Young, J. M., Friedman, C., Williams, E. M., Ross, J. A., Tonnes-Priddy, L., and Trask, B. J. (2002). Different evolutionary processes shaped the mouse and human olfactory receptor gene families. Hum. Mol. Genet. 11, 535-546. Erratum in: Hum. Mol. Genet. 11:1683. doi: 10.1093/hmg/11.5.535

Young, J. M., Luche, R. M., and Trask, B. J. (2011). Rigorous and thorough bioinformatic analyses of olfactory receptor promoters confirm enrichment of $\mathrm{O} / \mathrm{E}$ and homeodomain binding sites but reveal no new common motifs. $B M C$ Genomics 12:561. doi: 10.1186/1471-2164-12-561

Zhang, G., Titlow, W. B., Biecker, S. M., Stromberg, A. J., and McClintock, T. S. (2016). Lhx2 determines odorant receptor expression frequency in mature olfactory sensory neurons. eNeuro 3. doi: 10.1523/eneuro.0230-16.2016

Zhang, X., and Firestein, S. (2002). The olfactory receptor gene superfamily of the mouse. Nat. Neurosci. 5, 124-133.

Zhang, X., Rodriguez, I., Mombaerts, P., and Firestein, S. (2004). Odorant and vomeronasal receptor genes in two mouse genome assemblies. Genomics 83 , 802-811. doi: 10.1016/j.ygeno.2003.10.009

Zhang, X., Zhang, X., and Firestein, S. (2007). Comparative genomics of odorantand pheromone receptor genes in rodents. Genomics 89, 441-450. doi: 10.1016/ j.ygeno.2007.01.002

Conflict of Interest Statement: The authors declare that the research was conducted in the absence of any commercial or financial relationships that could be construed as a potential conflict of interest.

The reviewer ZW and handling Editor declared their shared affiliation, and the handling Editor states that the process nevertheless met the standards of a fair and objective review.

Copyright (C) 2017 Degl'Innocenti and D'Errico. This is an open-access article distributed under the terms of the Creative Commons Attribution License (CC BY). The use, distribution or reproduction in other forums is permitted, provided the original author(s) or licensor are credited and that the original publication in this journal is cited, in accordance with accepted academic practice. No use, distribution or reproduction is permitted which does not comply with these terms. 